\title{
Radical Cation Stabilization in a Cucurbituril Oligoaniline Rotaxane
}

\author{
Rienk Eelkema, Kiminori Maeda, Barbara Odell, and Harry L. Anderson* \\ Department of Chemistry, Chemistry Research Laboratory, University of Oxford, \\ 12 Mansfield Road, Oxford, OX1 3TA (UK) \\ harry.anderson@chemistry.oxford.ac.uk
}

\section{Contents}

page

Section 1 Synthetic procedures

1.1 General remarks

S1

1.2 Synthetic procedures

S1

1.3 NMR spectra

S4

Section 2 HPLC traces

S6

Section 3 Binding titrations

S7

Section 4 Electrochemistry

S8

Section 5 UV/VIS spectroscopy

S8

Section 6 EPR spectroscopy

S9

Section 7 References

S9

\section{Section 1: Synthetic Procedures}

\subsection{General remarks}

All reagents were purchased from commercial sources and were used as provided unless otherwise stated. All solvents were deoxygenated using standard freeze-thaw techniques. Thin layer chromatography was performed using aluminium-foil backed plates precoated with Kieselgel $60 \mathrm{~F}_{254}$. Flash column chromatography was carried out with silica gel 60 (230-400 mesh) from Aldrich. ${ }^{1} \mathrm{H}$ NMR spectra were recorded on Bruker DPX400, DRX500 and AV500 NMR spectrometers, operating at $400.13,500.13$ and $500.30 \mathrm{MHz}$, respectively. ${ }^{13} \mathrm{C}$ NMR spectra were recorded on an AV500 NMR spectrometer with a ${ }^{13} \mathrm{C}\left\{{ }^{1} \mathrm{H}\right\}$ cryoprobe, operating at $125.80 \mathrm{MHz}$. COSY and Tr-ROESY were performed on a Bruker AV500. All NMR spectra were recorded at $25^{\circ} \mathrm{C}$. Chemical shift values are denoted in $\delta$ values $(\mathrm{ppm})$ relative to residual solvent peaks (DMSO- $d_{6},{ }^{1} \mathrm{H} \delta=2.50,{ }^{13} \mathrm{C} \delta=39.51 ; 1 \mathrm{M} \mathrm{DCl} / \mathrm{D}_{2} \mathrm{O}$ was referenced to internal dioxane, ${ }^{1} \mathrm{H} \delta=3.75,{ }^{13} \mathrm{C} \delta=$ 67.19). Low and high resolution ESI-MS were carried out on a Fisons platform and Micromass LCT platform, respectively. MALDI-ToF spectra were recorded at the EPSRC National Mass Spectrometry Service Centre at Swansea on a Voyager-DE-STR. UV-VIS-NIR spectra were recorded on a Perkin Elmer Lamda-6 spectrophotometer, using $1.0 \mathrm{~cm}$ quartz cuvettes. Elemental analysis was performed by ICL Analytical Services, Oxford. Molecular structure modelling was performed in MacroModel, with the MMFF force field ${ }^{1}$ using water as the solvent.

\subsection{Synthetic procedures}

Dumbbell 1 and Halfdumbbell 4

A two-necked flask was filled with degassed $\mathrm{MeOH}(5 \mathrm{~mL}), 4,4$ '-diaminodiphenylamine $2^{2}$ (100 mg, 0.50 $\mathrm{mmol})$, aldehyde $3^{3}(216 \mathrm{mg}, 0.50 \mathrm{mmol})$ and acetic acid $(180 \mathrm{mg}, 3.00 \mathrm{mmol})$, and cooled to $0^{\circ} \mathrm{C}$. After 
addition of solid $\mathrm{NaBH}_{3} \mathrm{CN}$ (94 mg, $1.50 \mathrm{mmol}$ ) the mixture was allowed to warm up to room temperature over night, then added to $25 \mathrm{~mL} \mathrm{CH} \mathrm{Cl}_{2}$, washed with $5 \% \mathrm{NaOH}$ (aq., $2 \times 10 \mathrm{~mL}$ ), water $(2 \times 10 \mathrm{~mL}$ ) and brine, and dried over $\mathrm{MgSO}_{4}$. Evaporation of the solvent yielded a mixture of $\mathbf{1}$ and $\mathbf{4}$ in approximate $1: 2$ ratio as a yellow/brown oil. Purification by column chromatography $\left(\mathrm{SiO}_{2}, \mathrm{CHCl}_{3}\right.$ :acetone: $\left.\mathrm{Et}_{3} \mathrm{~N}=40: 1: 1\right)$ yielded pure 1 (103 $\mathrm{mg}, 0.10 \mathrm{mmol}, 20 \%$ yield) and pure 4 (132 $\mathrm{mg}, 0.22 \mathrm{mmol}, 43 \%$ yield), both as yellow oils.

Halfdumbbell 4, $N^{1}$-(4-aminophenyl)- $N^{4}$-(3,5-bis(2-(2-(2-methoxyethoxy)-ethoxy)ethoxy)benzyl)benzene-1,4diamine

${ }^{1} \mathrm{H} \mathrm{NMR}\left(1 \mathrm{M} \mathrm{DCl} / \mathrm{D}_{2} \mathrm{O}, 500 \mathrm{MHz}\right) \delta 7.28(\mathrm{~d}, \mathrm{~J}=8.8 \mathrm{~Hz}, 2 \mathrm{H})$, 7.12 (d, J=3.2 Hz, $2 \mathrm{H}), 7.10$ (d, J=2.8 Hz, $2 \mathrm{H}$ ), 7.05 (d, J=9.1 $\mathrm{Hz}, 2 \mathrm{H}), 6.50(\mathrm{t}, J=1.9 \mathrm{~Hz}, 1 \mathrm{H}), 6.49(\mathrm{~d}, \mathrm{~J}=1.9 \mathrm{~Hz}, 2 \mathrm{H}), 4.47$ (s, $2 \mathrm{H}), 4.02-4.06(\mathrm{~m}, 4 \mathrm{H}), 3.63-3.66(\mathrm{~m}, 4 \mathrm{H}), 3.57-3.61(\mathrm{~m}, 8 \mathrm{H})$, 3.52-3.55 (m, $4 \mathrm{H}), 3.31(\mathrm{~s}, 6 \mathrm{H}) ;{ }^{13} \mathrm{C}$ NMR $\left(1 \mathrm{M} \mathrm{DCl} / \mathrm{D}_{2} \mathrm{O}, 126\right.$ $\mathrm{MHz}) \delta 159.9,144.3,143.4,132.7,126.1,125.0,124.7,123.0$,

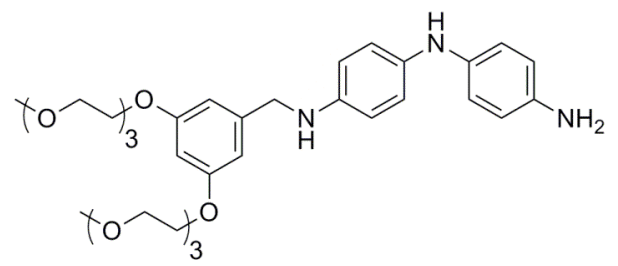
119.0, 118.2, 110.4, 103.7, 71.6, 70.3, 70.1, 70.0, 69.4, 67.9, 58.7, 55.6; HPLC retention time: 5.7 min; HRMS $(\mathrm{ESI}+) \mathrm{m} / \mathrm{z}[\mathrm{M}+\mathrm{H}]^{+}$calcd for $\mathrm{C}_{33} \mathrm{H}_{48} \mathrm{~N}_{3} \mathrm{O}_{8}$ 614.3436; found 614.3432; $\lambda_{\max }($ water/AcOH, pH = 3.5) $288 \mathrm{~nm}(\varepsilon=$ 17,900);

Dumbbell $\quad 1, \quad N^{1}$-(3,5-bis(2-(2-(2-methoxyethoxy)ethoxy)ethoxy)benzyl)- $N^{4}$-(4-(3,5-bis(2-(2-(2methoxyethoxy)ethoxy)ethoxy)benzylamino)phenyl)benzene-1,4-diamine

${ }^{1} \mathrm{H}$ NMR (DMSO- $d_{6} / 2 \%$ TFA, $\left.500 \mathrm{MHz}\right) \delta 7.23$

(d, $J=8.8 \mathrm{~Hz}, 4 \mathrm{H}), 7.07(\mathrm{~d}, J=8.8 \mathrm{~Hz}, 4 \mathrm{H}), 6.65$

(d, J=1.9 Hz, $4 \mathrm{H}), 6.53(\mathrm{t}, \mathrm{J}=2.0 \mathrm{~Hz}, 1 \mathrm{H}), 4.39$

(s, $4 \mathrm{H}), 4.04-4.07(\mathrm{~m}, 8 \mathrm{H}), 3.70-3.73(\mathrm{~m}, 8 \mathrm{H})$,

3.55-3.58 (m, $8 \mathrm{H}), 3.49-3.53(\mathrm{~m}, 16 \mathrm{H}), 3.40-$

$3.43(\mathrm{~m}, 8 \mathrm{H}), 3.23(\mathrm{~s}, 12 \mathrm{H}) ;{ }^{1} \mathrm{H}$ NMR $(1 \mathrm{M} \mathrm{DCl} /$

$\left.\mathrm{D}_{2} \mathrm{O}, 400 \mathrm{MHz}\right) \delta 7.14(\mathrm{~d}, \mathrm{~J}=8.9 \mathrm{~Hz}, 4 \mathrm{H}), 7.08$

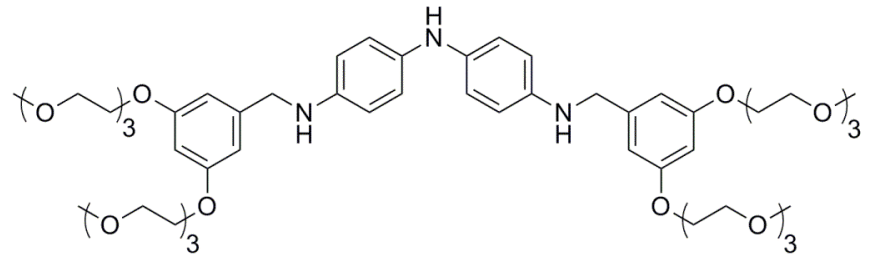

(d, J=8.5 Hz, $4 \mathrm{H}), 6.56(\mathrm{~s}, 2 \mathrm{H}), 6.50(\mathrm{~s}, 4 \mathrm{H}), 4.52(\mathrm{~s}, 4 \mathrm{H}), 4.05-4.09(\mathrm{~m}, 8 \mathrm{H}), 3.75-3.78(\mathrm{~m}, 8 \mathrm{H}), 3.63-3.66$ $(\mathrm{m}, 8 \mathrm{H}), 3.57-3.62(\mathrm{~m}, 16 \mathrm{H}), 3.52-3.55(\mathrm{~m}, 8 \mathrm{H}), 3.31(\mathrm{~s}, 12 \mathrm{H}) ;{ }^{13} \mathrm{C}$ NMR (DMSO- $\left.d_{6} / 2 \% \mathrm{TFA}, 126 \mathrm{MHz}\right) \delta$ 159.7, 142.2, 134.8, 129.3, 122.9, 117.6, 108.4, 101.2, 71.3, 70.0, 69.9, 69.7, 68.9, 67.3, 58.1, 53.5; HPLC retention time: $8.1 \mathrm{~min}$; HRMS (ESI+) $\mathrm{m} / \mathrm{z}[\mathrm{M}+\mathrm{H}]^{+}$calcd for $\mathrm{C}_{54} \mathrm{H}_{82} \mathrm{~N}_{3} \mathrm{O}_{16}$ 1028.57; found 1028.57; $\lambda_{\max }$ (water/AcOH, $\mathrm{pH}=3.5) 288 \mathrm{~nm}(\varepsilon=20,600)$.

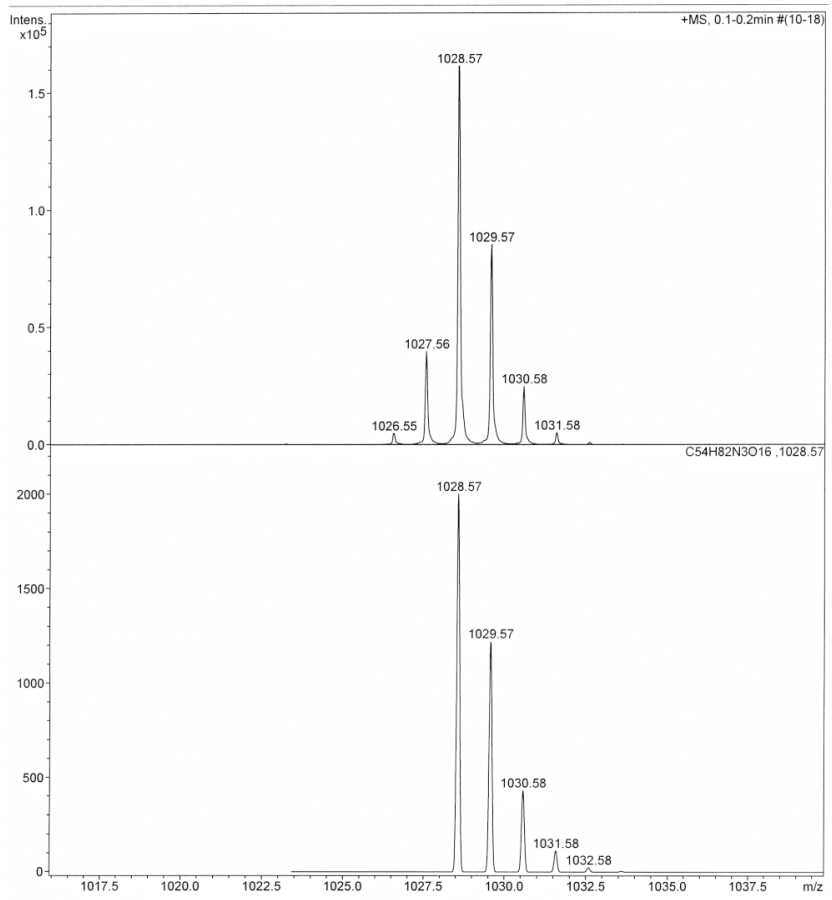

Figure S1: High resolution mass spectrum of dumbbell 1 (top) and calculated isotopic pattern (bottom). 
Rotaxane 1CCB[7]

A two-necked flask was filled with a solution of acetic acid in deionised water $(5.9 \mathrm{mM}, 400$ $\mathrm{mL}$ ) and the solution was thoroughly degassed. 4,4'-Diaminodiphenylamine 2 (50 $\mathrm{mg}, 0.25 \mathrm{mmol}$ ) and CB[7] (584 $\mathrm{mg}, 0.5 \mathrm{mmol}$, eq.) were added and the mixture was stirred until all solid was dissolved. Stopper aldehyde

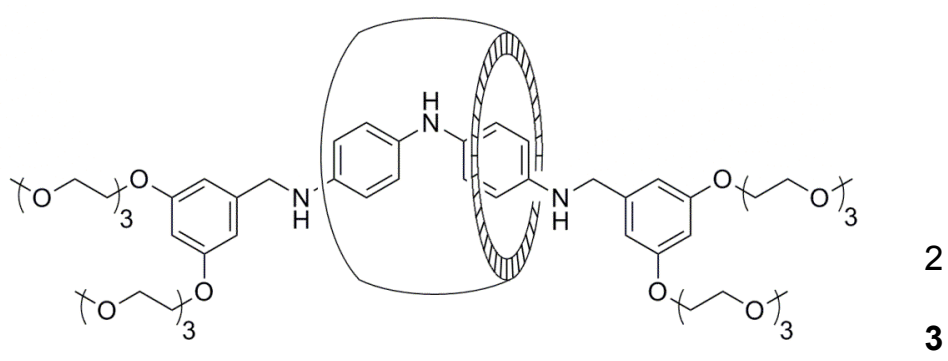
(205 mg, $0.48 \mathrm{mmol}, 1.9$ eq.) was added, and the resulting orange solution was cooled to $0^{\circ} \mathrm{C} . \mathrm{NaBH}_{3} \mathrm{CN}(63$ $\mathrm{mg}, 1.0 \mathrm{mmol}, 4$ eq.) was added and the reaction mixture was put in a refrigerator at $4^{\circ} \mathrm{C}$ under nitrogen. After 48 hours the mixture was allowed to warm up to room temperature, and after addition of $\mathrm{Na}_{2} \mathrm{~S}_{2} \mathrm{O}_{5}(100$ mg, to avoid accidental oxidation of the rotaxane), the mixture was brought to $\mathrm{pH} 10$ using $\mathrm{NaOH}$. This solution was washed with degassed $\mathrm{CH}_{2} \mathrm{Cl}_{2}(10 \times 3 \mathrm{~mL})$ and subsequently acidified to $\mathrm{pH} 1 \mathrm{using} 6 \mathrm{M} \mathrm{HCl}(\mathrm{aq})$. The mixture was stirred for $1 \mathrm{~h}$, subsequently the $\mathrm{pH}$ was brought back to $\mathrm{pH}$ 7-8 using solid $\mathrm{NaOH}$, after which the solvent was removed under reduced pressure. The rotaxane was extracted from the resultant white solid using degassed MeCN $(5 \times 10 \mathrm{~mL})$ to leave inorganic salts. Filtration through a $0.2 \mu \mathrm{m}$ nylon filter and subsequent evaporation of the solvent afforded rotaxane $1 \subset \mathrm{CB}[7]$ as a white powder (268 $\mathrm{mg}, 0.122 \mathrm{mmol}, 52 \%$ yield).

${ }^{1} \mathrm{H}$ NMR (1 M DCl / D $\left.\mathrm{O}, 500 \mathrm{MHz}\right) \delta 7.11(\mathrm{~d}, \mathrm{~J}=1.7 \mathrm{~Hz}, 4 \mathrm{H}), 7.07$ (dd, J=7.1, $\left.1.6 \mathrm{~Hz}, 4 \mathrm{H}\right), 6.74(\mathrm{~d}, \mathrm{~J}=9.0 \mathrm{~Hz}$, $4 \mathrm{H}), 6.72(\mathrm{~d}, \mathrm{~J}=2.4 \mathrm{~Hz}, 2 \mathrm{H}), 5.73$ (d, J=15.3 Hz, $14 \mathrm{H}), 5.53$ (s, $14 \mathrm{H}), 4.48$ (s, $4 \mathrm{H}), 4.29-4.33$ (m, $8 \mathrm{H}), 4.25$ (d, J=15.4 Hz, $14 \mathrm{H}), 3.92-3.96(\mathrm{~m}, 8 \mathrm{H}), 3.77-3.80(\mathrm{~m}, 8 \mathrm{H}), 3.71-3.74(\mathrm{~m}, 8 \mathrm{H}), 3.67-3.71(\mathrm{~m}, 8 \mathrm{H}), 3.59-3.63$ $(\mathrm{m}, 8 \mathrm{H}), 3.36$ (s, $12 \mathrm{H}) ;{ }^{1} \mathrm{H}$ NMR (DMSO-d $/ 2 \%$ TFA, $\left.500 \mathrm{MHz}\right) \delta 6.99(\mathrm{~d}, \mathrm{~J}=2.0 \mathrm{~Hz}, 4 \mathrm{H}), 6.94(\mathrm{~d}, \mathrm{~J}=8.8 \mathrm{~Hz}$, $4 \mathrm{H}), 6.65$ (d, J=8.8 Hz, $4 \mathrm{H}), 6.60$ (t, J=2.0 Hz, $2 \mathrm{H}), 5.63$ (d, J=14.7 Hz, $14 \mathrm{H}), 5.38$ (s, $14 \mathrm{H}), 4.32$ (s, $4 \mathrm{H}$ ), 4.10-4.23 (m, $22 \mathrm{H}), 3.75-3.80(\mathrm{~m}, 8 \mathrm{H}), 3.57-3.62(\mathrm{~m}, 8 \mathrm{H}), 3.50-3.57(\mathrm{~m}, 16 \mathrm{H}), 3.41-3.44(\mathrm{~m}, 8 \mathrm{H}), 3.23(\mathrm{~s}$, $12 \mathrm{H}$ ); ${ }^{13} \mathrm{C}$ NMR (DMSO-d $/ 2 \%$ TFA, $\left.126 \mathrm{MHz}\right) \delta 159.7,155.1,144.2,134.9,126.6,122.3,118.6,109.0$, $101.4,71.4,70.1,70.0,69.8,69.1,67.4,58.2,56.6,51.9$, due to overlap in the region from 69.5 to 70.5 ppm, one aliphatic carbon signal is missing; ${ }^{1} \mathrm{H}-{ }^{1} \mathrm{H}$ gCOSY (DMSO-d $/ 2 \%$ TFA, 500-500 MHz) $\delta 6.99 \leftrightarrow 6.60,6.94$ $\leftrightarrow 6.65,5.63 \leftrightarrow(4.10-4.23),(4.10-4.23) \leftrightarrow(3.75-3.80),(3.57-3.62) \leftrightarrow(3.50-3.57),(3.50-3.57) \leftrightarrow(3.41-3.44) ;$ 1D NOE (DMSO- $d_{6} / 2 \%$ TFA, Tr-ROESY, $500 \mathrm{MHz}, 25^{\circ} \mathrm{C}$ ), irr.@4.33 ppm: $\delta 6.99$ (strong), 6.94 (weak); irr.@5.63 ppm $\delta 6.99$ (weak), 6.94 (weak), 6.65 (weak), 4.18 (strong); HPLC retention time: 4.8 min; $\lambda_{\text {max }}\left(\mathrm{H}_{2} \mathrm{O}\right.$ / $\mathrm{AcOH}, \mathrm{pH}=3.5) 300 \mathrm{~nm}(\varepsilon=17,300)$; HRMS (ESI+) $\mathrm{m} / \mathrm{z}[\mathrm{M}]^{2+}$ calcd for $\mathrm{C}_{96} \mathrm{H}_{123} \mathrm{~N}_{31} \mathrm{O}_{30}{ }^{2+} 1095.45$; found 1095.43; MALDI-ToF $\left(\mathrm{MS}^{+}\right.$, matrix = DHB) $\mathrm{m} / \mathrm{z}[\mathrm{M}]^{-+}$calcd for $\mathrm{C}_{96} \mathrm{H}_{123} \mathrm{~N}_{31} \mathrm{O}_{30} 2190.9$; found 2190.9; [M+Na] calcd for $\mathrm{C}_{96} \mathrm{H}_{123} \mathrm{~N}_{31} \mathrm{O}_{30} \mathrm{Na}$ 2213.9; found 2213.9. Anal. calcd. for $\mathrm{C}_{96} \mathrm{H}_{123} \mathrm{~N}_{31} \mathrm{O}_{30} .6 \mathrm{H}_{2} \mathrm{O}: \mathrm{C}, 50.15 ; \mathrm{H}, 5.92 ; \mathrm{N}$, $18.88 \%$; found C, 49.97; H, 5.23; N, $17.84 \%$. 

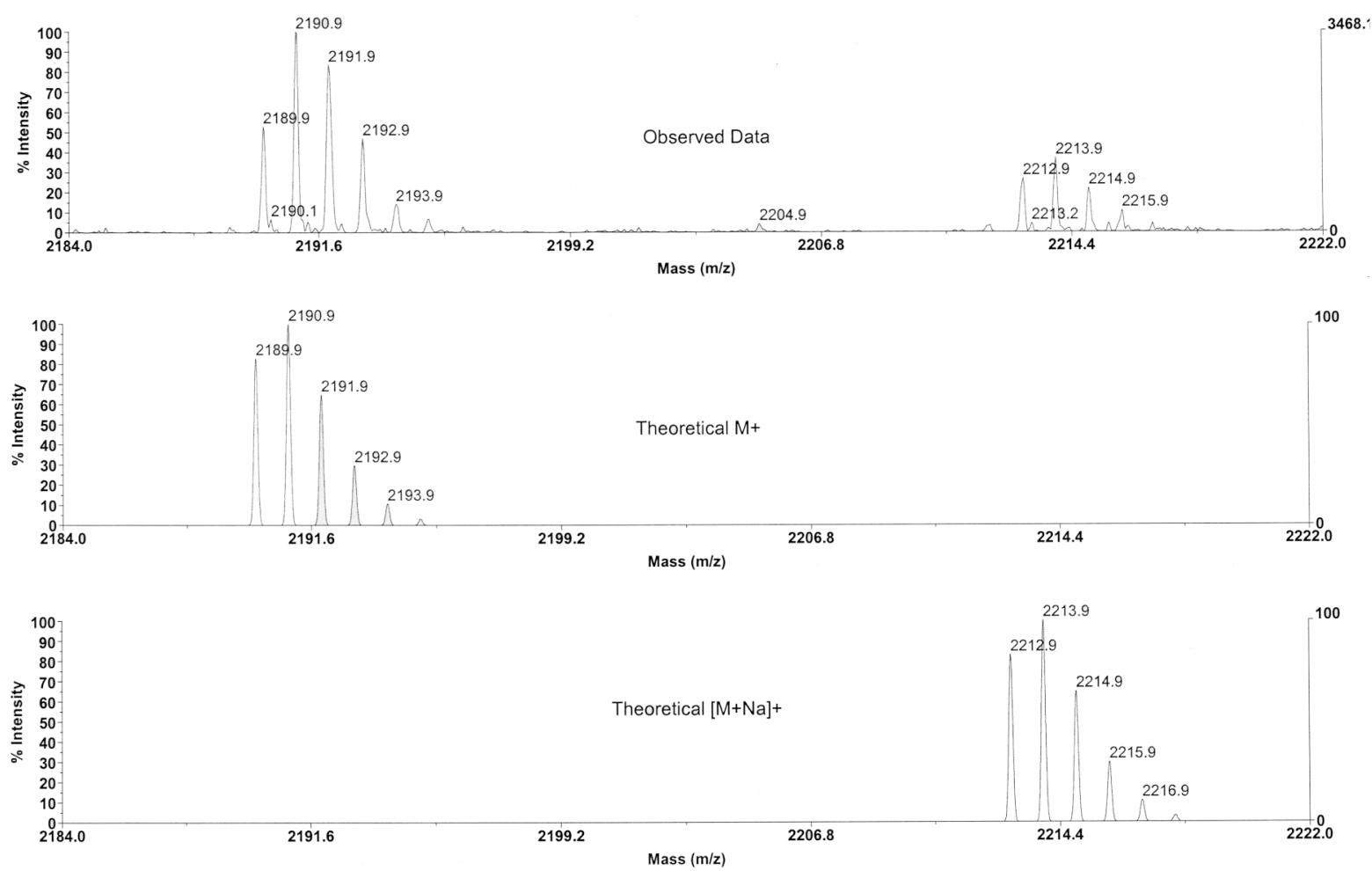

Figure S2: High resolution mass spectrum of rotaxane $1 \subset \mathrm{CB}[7]$ (top) and calculated isotopic patterns ([M] $]^{++}$ middle; $[\mathrm{M}+\mathrm{Na}]^{+}$, bottom).

\subsection{NMR Spectroscopy}

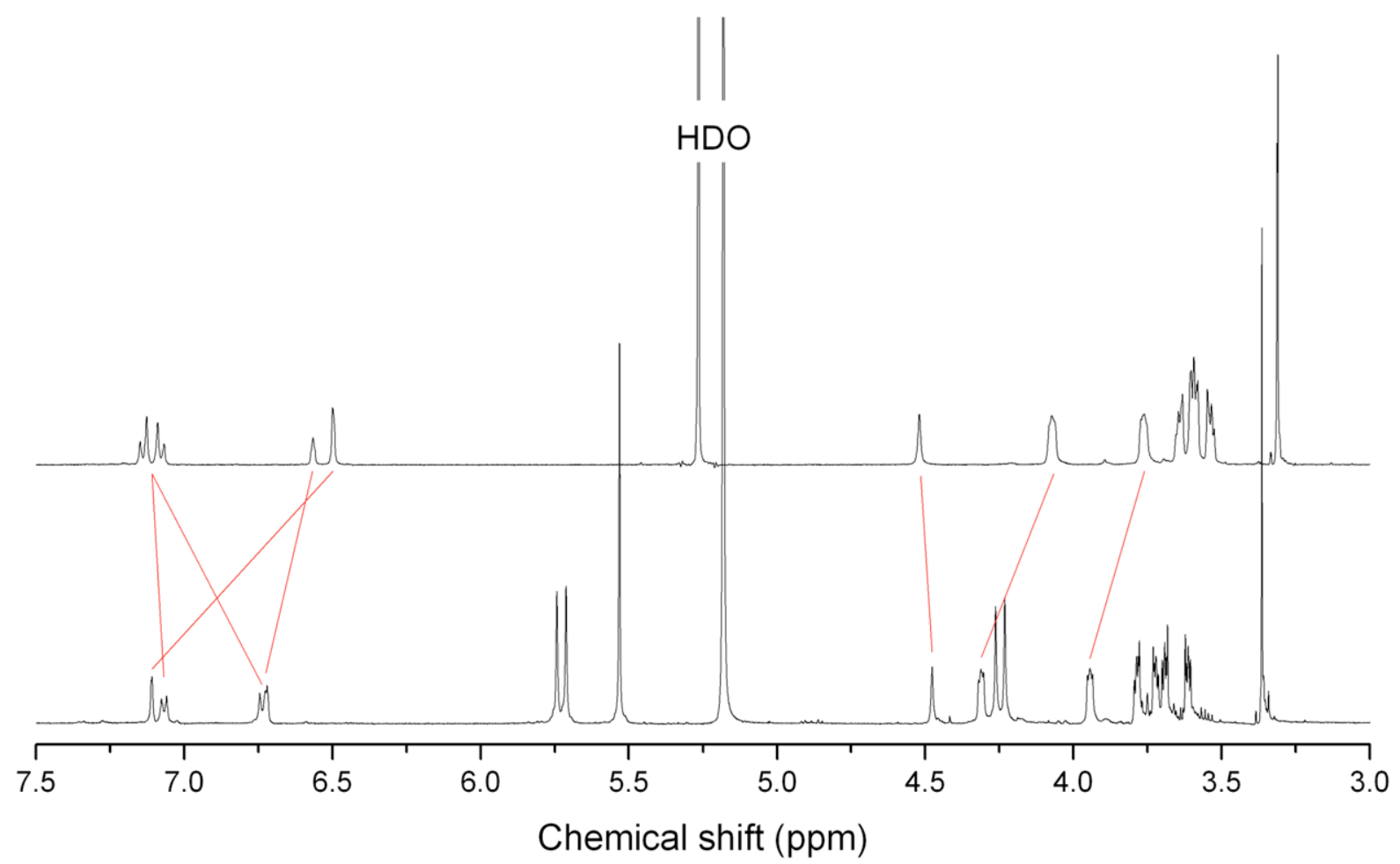

Figure S3: ${ }^{1} \mathrm{H}$ NMR spectra of dumbbell 1 (upper spectrum, $400 \mathrm{MHz}$ ) and rotaxane 1СCB[7] (lower spectrum, $500 \mathrm{MHz}$ ) in $1 \mathrm{M} \mathrm{DCl} / \mathrm{D}_{2} \mathrm{O}$. 


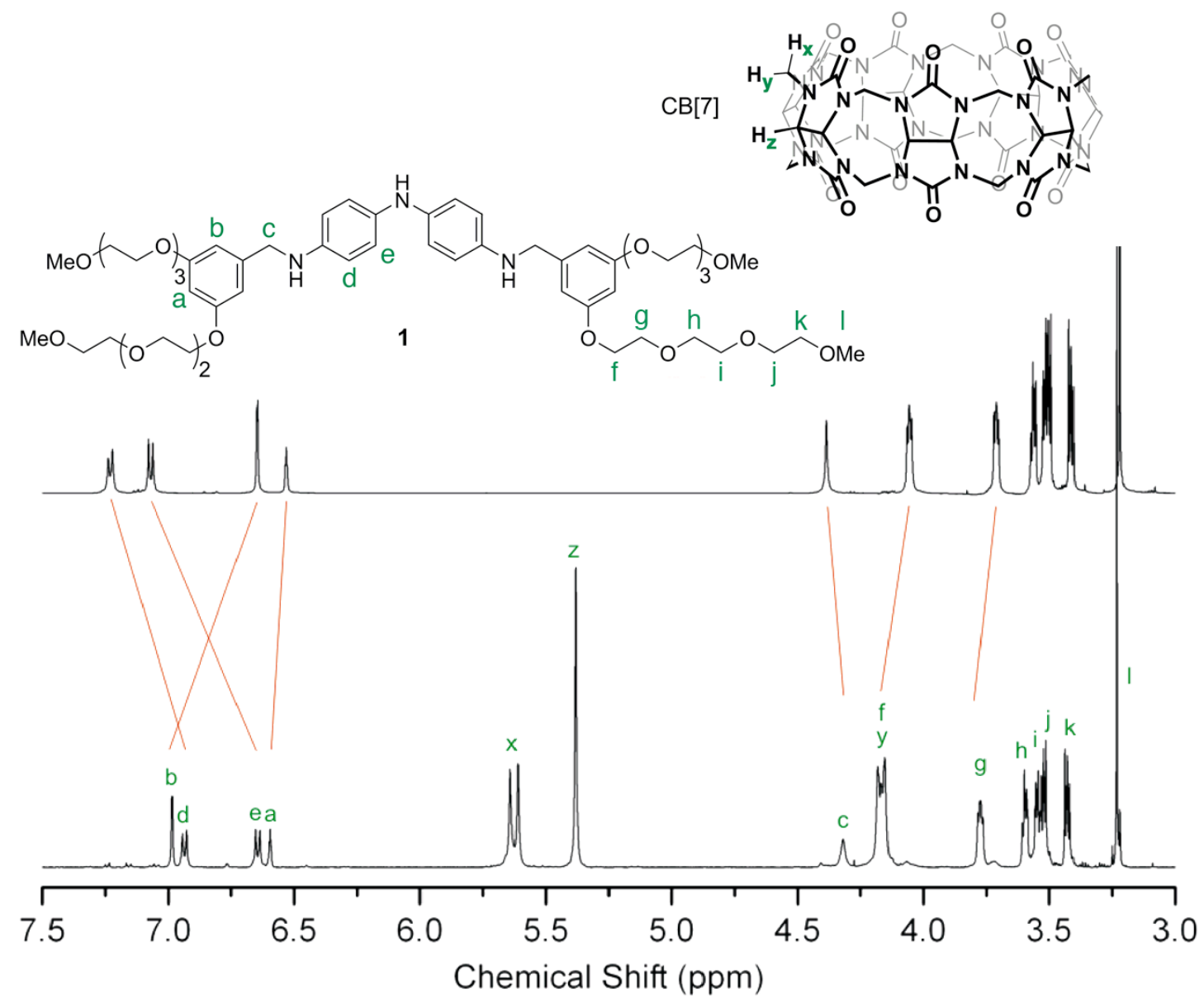

Figure S4: ${ }^{1} \mathrm{H}$ NMR spectra $(500 \mathrm{MHz})$ of dumbbell 1 (upper spectrum) and rotaxane 1СCB[7] (lower spectrum) in DMSO- $d_{6} / 2 \%$ TFA.

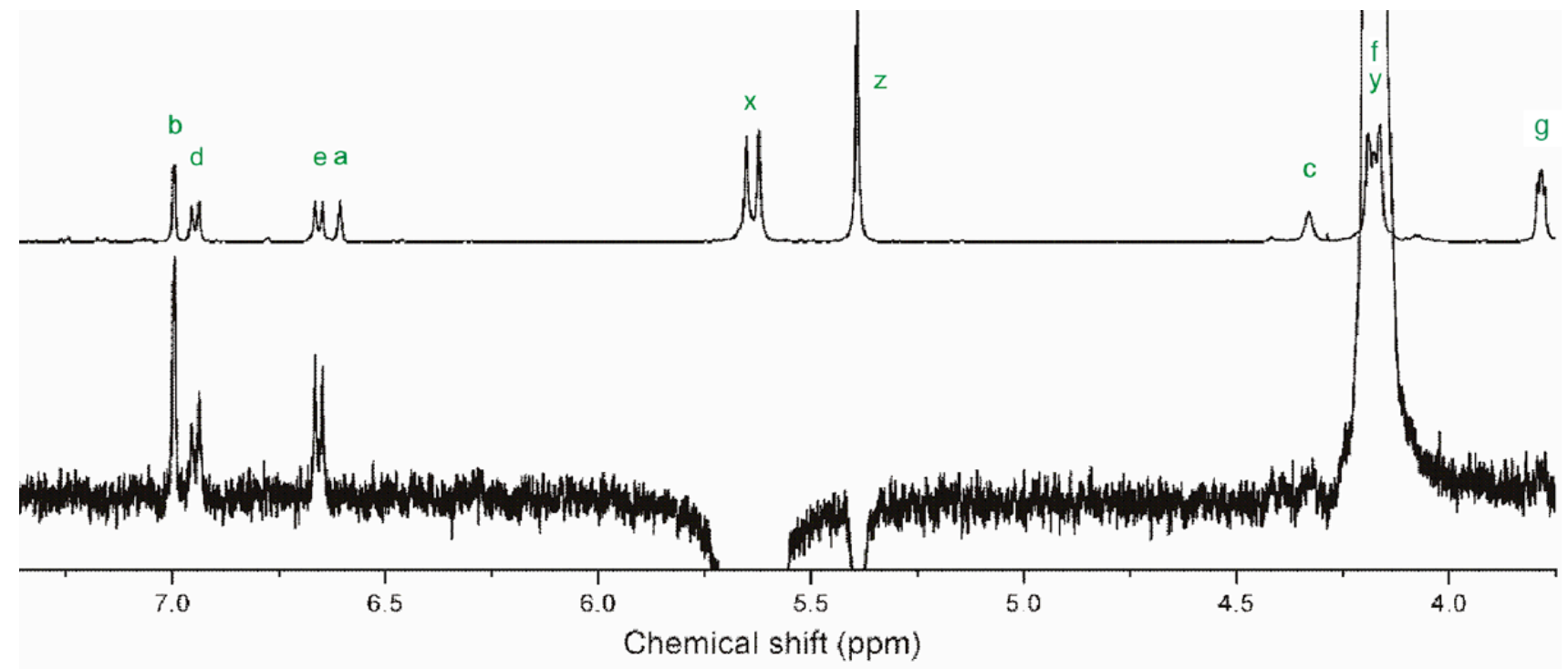

Figure S5: $1 \mathrm{D}$ gradient NOE spectrum of rotaxane $1 \mathrm{CCB}[7]$ (lower spectrum, $500 \mathrm{MHz}, 25^{\circ} \mathrm{C}, T_{\text {mix }}=500 \mathrm{~ms}$ ) in DMSO- $d_{6} / 2 \%$ TFA. The sample was irradiated at the frequency of the CB[7] proton that is parallel to the portal carbonyls $\left(\mathrm{H}_{\mathrm{x}}, \delta=5.63 \mathrm{ppm}\right)$. The upper spectrum shows a ${ }^{1} \mathrm{H}$ NMR spectrum of rotaxane $1 \subset \mathrm{CB}[7]$, for comparison. 


\section{Section 2: HPLC Traces}

Method: HPLC analyses were carried out on an HP 1100 series workstation using a Zorbax Eclipse XDB C8 analytical column $(4.6 \times 15 \mathrm{~mm}, 5$ micron). The analytes were eluted using a timetabled two-solvent gradient system (Figure S6) and monitored using a diode array detector using the indicated. CHAPS $=0.25 \% \mathrm{w} / \mathrm{V}$ dicyclohexylammonium phosphate in ultrapure water.

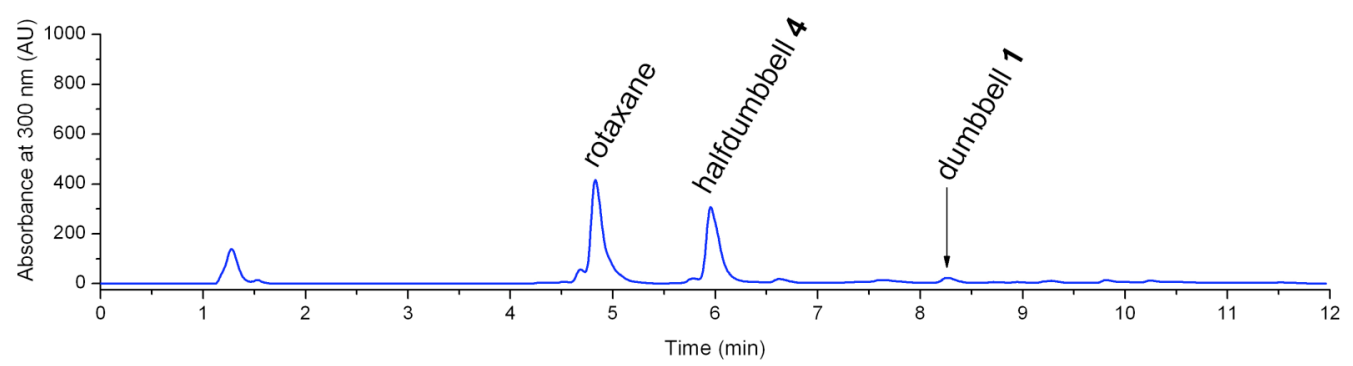

Figure S7: Synthesis of 1СCB[7], HPLC trace of the crude reaction mixture after 48 hours reaction time.

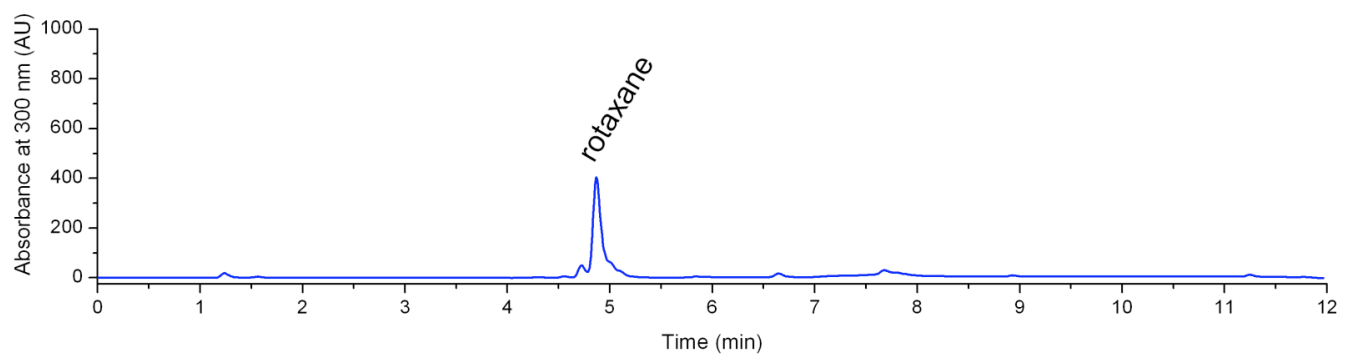

Figure S8: HPLC trace of rotaxane 1СCB[7] after purification.

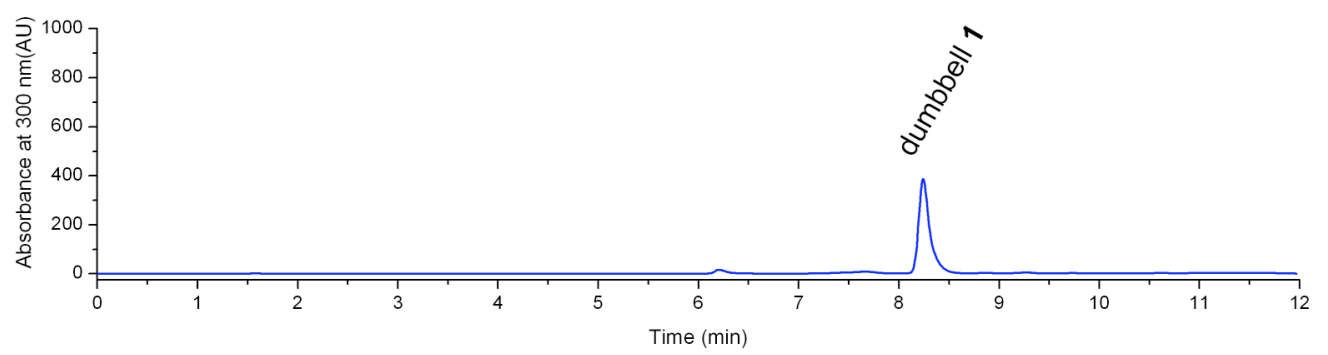

Figure S9: HPLC trace of dumbbell 1 after purification.

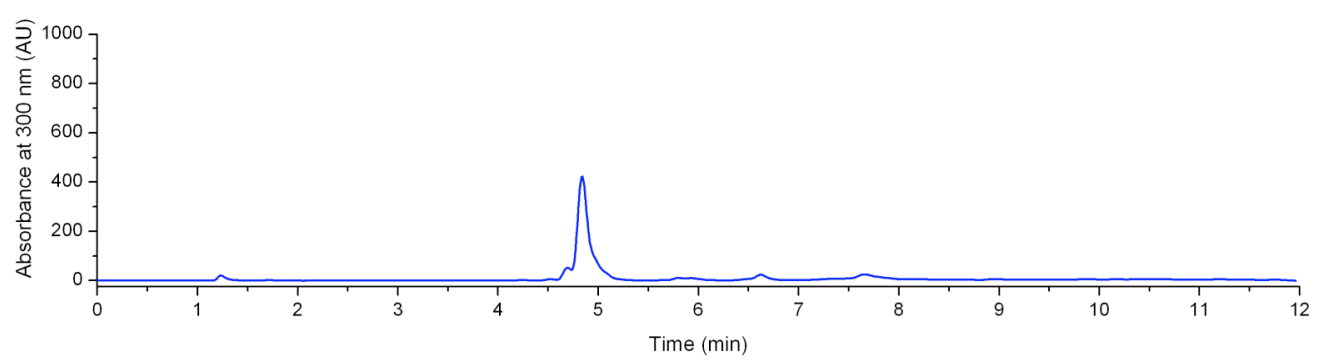

Figure S10: HPLC trace of rotaxane $1 \subset \mathrm{CB}[7]$ after heating $\left(80^{\circ} \mathrm{C}\right)$ in $\mathrm{MeCN}$ for 48 hours. The MeCN was deoxygenated and a small amount of $\mathrm{Na}_{2} \mathrm{~S}_{2} \mathrm{O}_{5}$ was added to further prevent oxidation of the rotaxane. 


\section{Section 3: Binding Titrations}

Binding constants were determined by UV-VIS titration of the host into a solution of the guest. Titrations were performed at constant guest concentration, typically around $5 \times 10^{-5} \mathrm{M}$, in degassed water containing acetic acid $(5.9 \mathrm{mM})$ and $\mathrm{NaBH}_{3} \mathrm{CN}(2.5 \mathrm{mM})$ at $298 \mathrm{~K}$. Binding constants were calculated by fitting to a $1: 1$ binding isotherm in Origin 7.5 at a single wavelength, and confirmed by fitting to a $1: 1$ binding isotherm in SpecFit/32 over the $250-320 \mathrm{~nm}$ range.
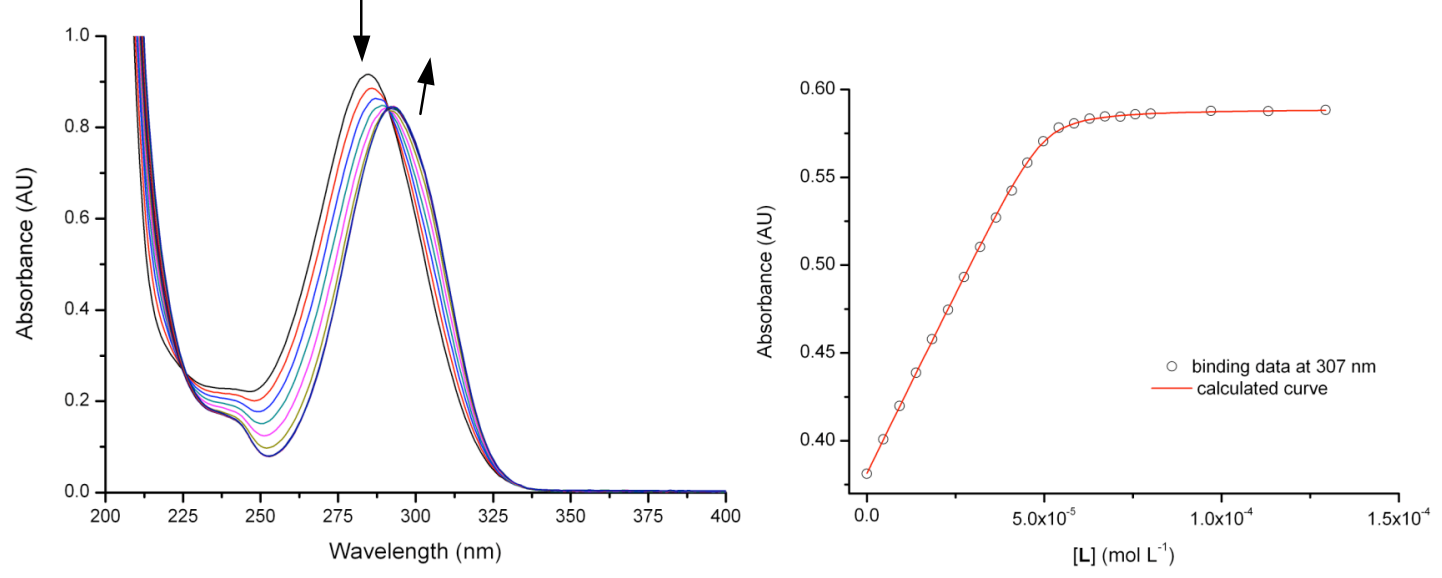

Figure S11: UV-VIS titration of CB[7], $\mathrm{L}$ with 4,4'-diaminodiphenylamine 2 ([2] $\left.=5.0 \times 10^{-5} \mathrm{M}, 298 \mathrm{~K}\right)$. The data at $307 \mathrm{~nm}$ were fitted to a $1: 1$ binding isotherm to give a binding constant $K=2.2 \pm 0.2 \times 10^{6} \mathrm{M}^{-1}$; the binding constant is too high to determine accurately from this experiment, so this value should be regarded as a lower limit. Arrows indicate areas of increasing and decreasing absorption during the titration.
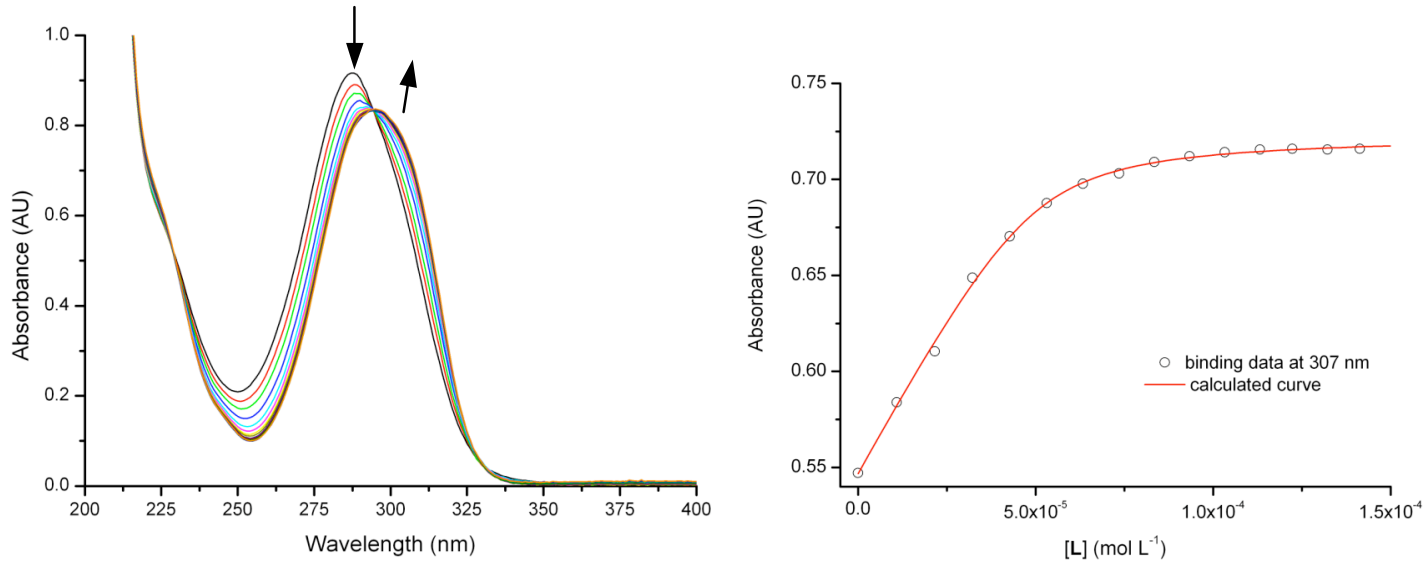

Figure S12: UV-VIS titration of CB[7], L with halfdumbbell 4 ([4] $\left.=5.13 \times 10^{-5} \mathrm{M}, 298 \mathrm{~K}\right)$. The data at $307 \mathrm{~nm}$ were fitted to a $1: 1$ binding isotherm to give a binding constant $K=2.8 \pm 0.6 \times 10^{5} \mathrm{M}^{-1}$. Arrows indicate areas of increasing and decreasing absorption during the titration. 

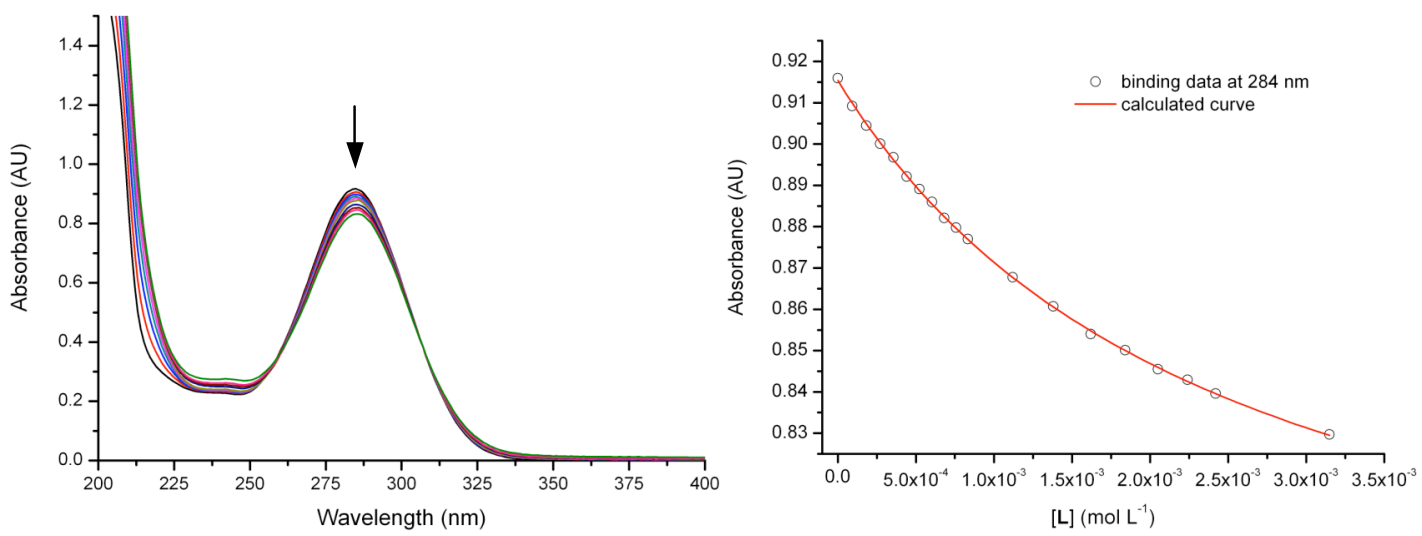

Figure S13: UV-VIS titration of $\beta$-cyclodextrin, $\mathbf{L}$ with 4,4'-diaminodiphenylamine $2\left([2]=5.0 \times 10^{-5} \mathrm{M}, 298 \mathrm{~K}\right)$. The data at $284 \mathrm{~nm}$ were fitted to a 1:1 binding isotherm to give a binding constant $K=4.1 \pm 0.1 \times 10^{2} \mathrm{M}^{-1}$. Arrows indicate areas of increasing and decreasing absorption during the titration.

\section{Section 4: Electrochemistry}

Due to the limited solubility of dumbbell 1 in water at $\mathrm{pH} 7.0$, electrochemical experiments were conducted in DMSO.

Square wave voltammetry experiments were performed using an Autolab PGSTAT12 potentiostat, operating with step potential $10 \mathrm{mV}$, step amplitude $50 \mathrm{mV}$, squarewave frequency $8 \mathrm{~Hz}$; Compounds were dissolved in DMSO containing $\mathrm{Bu}_{4} \mathrm{NBF}_{4}(0.1 \mathrm{M})$, under argon, typically at a concentration of $1-2 \mathrm{mM}$. A $3 \mathrm{~mm}$ glassy carbon working electrode was used with a $\mathrm{Pt}$ wire counter electrode and a $\mathrm{Ag} / \mathrm{AgNO}_{3}$ pseudoreference electrode. The potentials were referenced directly to internal ferrocene.

\section{Section 5: UVIVIS Spectroscopy}
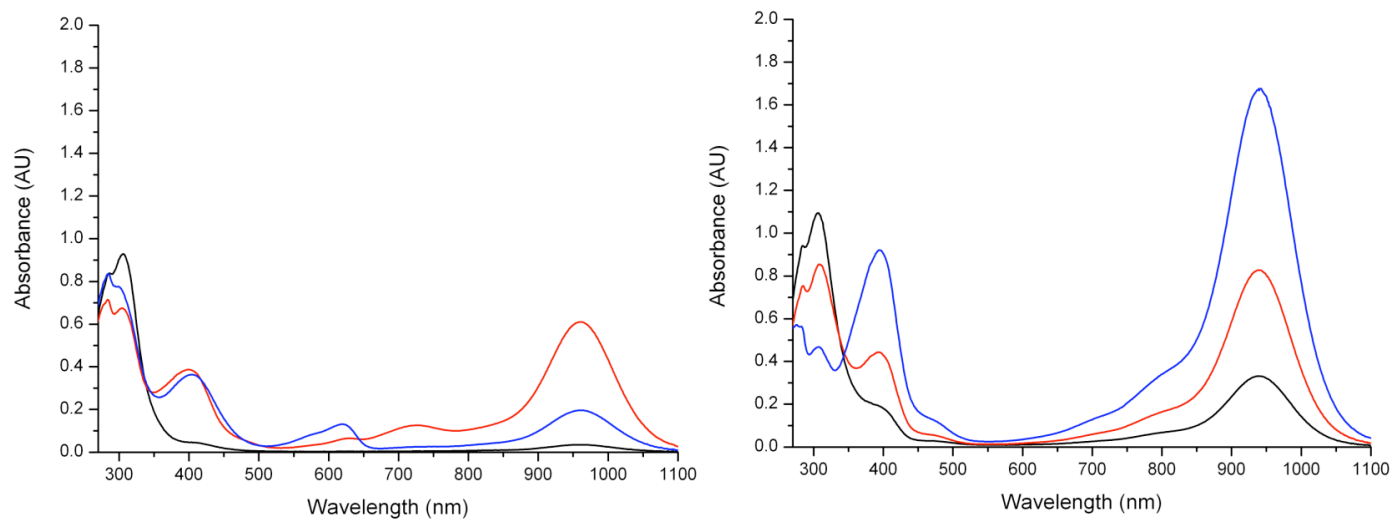

Figure S14: Oxidation of dumbbell 1 and rotaxane 1СCB[7] in DMSO. The figure shows UV-VIS absorption spectra of dumbbell 1 (left) and rotaxane 1СCB[7] (right) upon oxidation with 10 eq. $\left(\mathrm{NH}_{4}\right)_{2} \mathrm{~S}_{2} \mathrm{O}_{8}$ in DMSO, after 0 (black), 10 (red) and $30 \mathrm{~min}$ (blue). For dumbbell 1, the initial formation of a $1^{{ }^{++}}$species (950 nm) was quickly followed by a decline in the absorption at $950 \mathrm{~nm}$, and the formation of $1^{2+}(720 \mathrm{~nm})$ and an additional species at $610 \mathrm{~nm}$. For rotaxane $1 \subset \mathrm{CB}[7]$, no significant formation of $(1 \subset \mathrm{CB}[7])^{2+}$ was observed. Instead, more $(1 \subset \mathrm{CB}[7])^{\cdot+}$ was formed over time. 


\section{Section 6: EPR}

Due to the limited solubility of dumbbell 1 in water at pH 7.0, EPR experiments were conducted in DMSO.

X-band CW-EPR spectra were recorded on a Bruker EMX premium X, operating at $9.8785 \mathrm{GHz}$ with a modulation amplitude of $1 \mathrm{G}$, using glass capillaries with an inner diameter of $1 \mathrm{~mm}$. [analyte] $=4.3 \times 10^{-3} \mathrm{M}$ in DMSO.
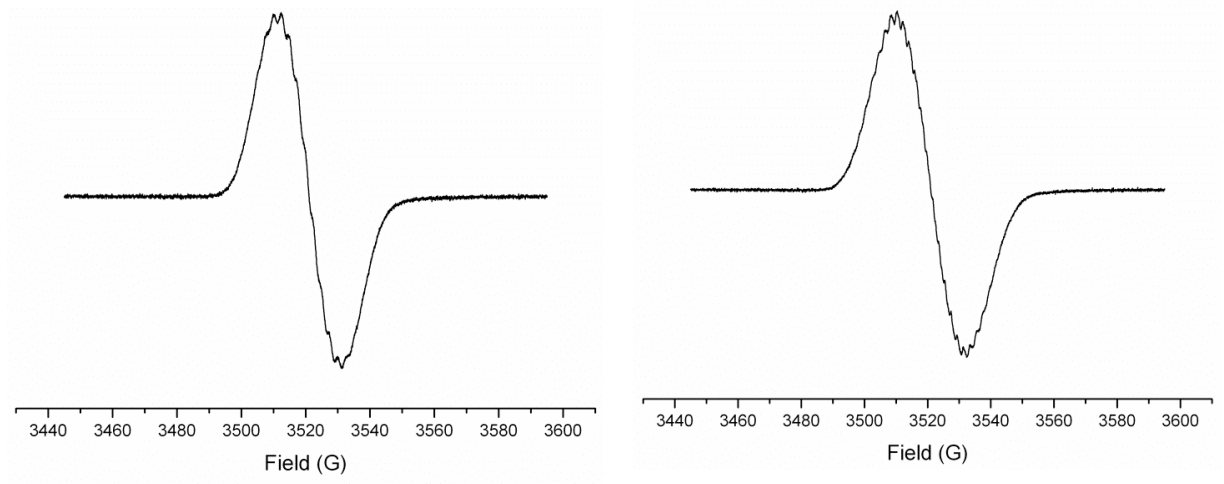

Figure S15: EPR spectra of dumbbell 1 (left) and rotaxane 1СCB[7] (right). For dumbbell 1, $g=2.0044$; for rotaxane $1 \subset \mathrm{CB}[7], g=2.0045$.

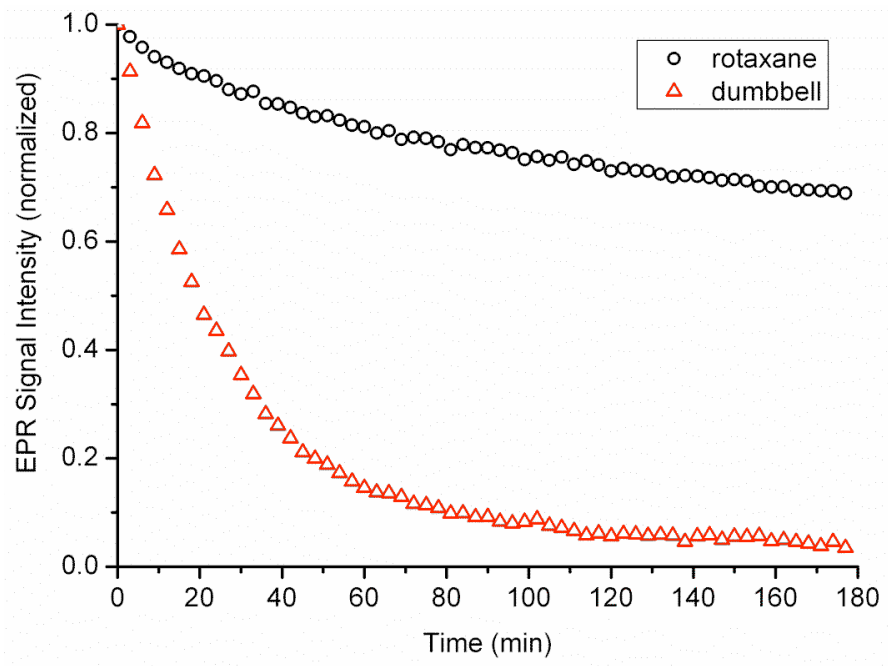

Figure S16: EPR signal decay of dumbbell 1 (red) and rotaxane 1СCB[7] (black) in time, after oxidation in DMSO. For dumbbell $1,1^{*+}$ had to be generated by addition of $\left(\mathrm{NH}_{4}\right)_{2} \mathrm{~S}_{2} \mathrm{O}_{8}$. In the case of rotaxane 1СCB[7], molecular oxygen present in the system generated $(1 \subset \mathrm{CB}[7])^{\circ+}$ upon addition of rotaxane $1 \subset \mathrm{CB}[7]$ to $\mathrm{DMSO}$.

\section{Section 7: References}

(1) Halgren, T. A. J. Comput. Chem. 1996, 17, 520-552.

(2) Kulszewicz-Bajer, I.; Rozalska, I.; Kurylek, M. New J. Chem. 2004, 28, 669-675.

(3) Nielsen, C. B.; Johnsen, M.; Arnbjerg, J.; Pittelkow, M.; Mcllroy, S. P.; Ogilby, P. R.; Jørgensen, M. J. Org. Chem. 2005, 70, 7065-7079. 